\title{
Mantle sources of Cenozoic volcanic activities around the South China Sea revealed by geochemical and isotopic data using the principal component analysis (PCA)
}

\section{Shuangshuang Chen}

Sun Yat-sen University

Zewei Wang ( $\square$ wangzw@sustech.edu.cn )

Southern University of Science and Technology

Rui Gao

Sun Yat-sen University

\section{Research Article}

Keywords: Volcanic rocks, geochemical indicators, mantle source, principal component analysis, South China Sea

Posted Date: January 22nd, 2021

DOI: https://doi.org/10.21203/rs.3.rs-148976/v1

License: (a) (1) This work is licensed under a Creative Commons Attribution 4.0 International License.

Read Full License 


\section{Abstract}

Principal component analysis (PCA) was conducted to analyze geochemical and isotopic data and interpret the characteristics and types of mantle sources of Cenozoic volcanic activities around the South China Sea (SCS). Fifteen trace element indicators and five isotopic indicators were surveyed from 623 volcanic rock samples obtained from the SCS, Hainan Island, Fujian-Zhejiang, Taiwan, Vietnam, and Thailand to characterize the geochemical properties of the volcanic rocks, determine the types of mantle sources, and assess the influence degree of each mantle source. Two principal components (PCs) were extracted by PCA based on trace elements and $\mathrm{Sr}-\mathrm{Nd}-\mathrm{Pb}$ isotopic ratios, which are an enriched oceanic island basalt-type mantle plume and a depleted mid-ocean ridge basalt-type spreading ridge. In the Southeast Asian region, the influence of Hainan mantle plume on younger volcanic activities (<13 Ma) was greater than that on older ones (>13 Ma) in the same location. PCA was used to verify the mantle plume-ridge interaction model of volcanic activities beneath the expansion center of the SCS and refute the hypothesis that the tension in the SCS is triggered by the Hainan plume. The results of this study demonstrate the efficiency and applicability of PCA to the discussion of mantle sources of volcanic activities and provide a new method with which to analyze geochemical data.

\section{Introduction}

Extensive and voluminous Cenozoic basalts are widely distributed within the Southeast Asian region (Fig. 1; Sun et al., 2009; Ho et al., 2000; Fedorov and Koloskov, 2005; Zou and Fan, 2010; Wang et al., 2012; Zhang et al., 2018), including the South China Sea (SCS) Basin (Yan et al., 2008; Zhang et al., 2017, 2018), Hainan Island, Leizhou Peninsula (Wang et al., 2012; Li et al., 2013; Liu et al., 2015; Zou and Fan, 2010), Fujian-Zhejiang (Huang et al., 2017; Ho et al., 2003), Taiwan (Tian et al., 2019), Vietnam (An et al., 2017; Hoang et al., 2018), and Thailand (Yan et al., 2018). The detailed geological setting of Southeast Asia is present in Supplementary I. The SCS shows evidence of a diverse array of spatially and temporally complex tectonic processes, including continental rifting, seafloor spreading, subduction, and terrane collision, all of which make up what is called a complete Wilson cycle (Li et al., 2014a, b; Yan et al., 2018; Zhou et al., 2009). The SCS is a highly complex research area worthy of in-depth study. Previous scientists proposed a variety of tectonic dynamic hypotheses to explain the Cenozoic volcanic activities in the SCS and its surroundings on the basis of multiple geochemical and geophysical study methods; these hypotheses include the upwelling of the mantle plume (Yan et al., 2018; Zhou et al., 2009), the retreat and withdrawal of the subducted Paleo-Pacific Plate (Shi and Li, 2012), tectonic extrusion related to the India-Eurasia collision (Briais et al.,1993), seafloor tension as a result of the subduction of the proto-SCS (Hall, 2002), and the mantle plume-spreading ridge interaction model (Yan et al., 2018; Yu et al., 2018; Zhang et al., 2018). However, the genesis of volcanic activities in the SCS and its surrounding areas remain controversial and ambiguous. For example, the dynamic mechanism triggering the expansion of the SCS is yet unknown, and the connection between the Hainan mantle plume and the expansion of the SCS is incompletely understood. Moreover, the influence of the Hainan mantle plume on volcanic activities in Southeast Asia has not been studied in detail. Given these knowledge gaps, analysis 
of the geochemical data of Cenozoic volcanic rocks covering a wide range of areas surrounding the SCS is necessary. Geochemical data contain multiple correlated indicators, such as trace elements and isotopes. Hence, extracting information from these data, such as the independent factors contributing to the rock contents, requires an advanced method. The present study employs a novel research method, i.e., principal component analysis (PCA), to explore the characteristics and properties of the mantle sources of volcanic activities in the SCS and its surrounding regions.

PCA, an important method of multivariate statistical analysis, is an effective dimension-reduction technique and a comprehensive evaluation strategy (Abdi and Williams, 2010). This method can easily identify the most "main" elements and structures of a dataset, remove noise and redundancy, reduce the number of dimensions of the original data, and reveal the simple structures hidden behind complex data (Abdi and Williams, 2010). Compared with other techniques, PCA presents the advantages of simplicity, no parameter limitation, and easy application to various analyses. Therefore, it is widely used and regarded as one of the most valuable applications of linear algebra (Zhao, 2016). Improvements in theory and the advancement of computer technologies have enabled the use of PCA to solve geoscience problems. As a powerful analytical tool, PCA may be applied to various branches of earth science, especially in the fields of meteorology and remote sensing (e.g., Abdi and Williams, 2010). For example, the PCA method could be applied to visualize multiband remote sensing data (Shimizu et al., 2010), solve the hydrochemical characteristics of groundwater systems (Peng et al., 2015), analyze atmospheric aerosols in Mexico City (Miranda et al., 2000), and describe the recurrent snowmelt pattern of multiyear remotely sensed snow cover (Woodruff and Qualls, 2019). Indeed, the application of PCA to geoscience represents a novel research approach characterized by diversified development and integration with new methods.

This study applies the PCA method to the analyses of geochemical data (e.g., trace elements and isotopes) and discover the characteristics of the mantle sources of the SCS and its surrounding areas. Determination of independent potential sources is often challenging because one chemical or isotopic indicator may originate from different sources, and one source can bring multiple trace elements and isotopes (Chen et al., 2020). Thus, we adopted PCA to replace the original variables (i.e., the contents of trace elements or isotopes) with a smaller number of derived variables that are easier to explain. These derived variables, called principal components (PCs), are linear combinations of the original variables. Each PC usually represents one independent geochemical or isotopic source for an indicator (Chen et al., 2020). The success of our analyses proves that the PCA method is effective, feasible, and applicable for dissecting geochemical data and understanding the nature of mantle sources of volcanic activities. More importantly, we introduced a new study method for the analyses of geochemical data.

\section{Results}

\subsection{PCA of trace elements}


Fifteen trace element indicators ( $\mathrm{Rb}, \mathrm{Nb}, \mathrm{Ba}, \mathrm{Hf}, \mathrm{Th}, \mathrm{U}, \mathrm{La}, \mathrm{Ce}, \mathrm{Nd}, \mathrm{Sm}, \mathrm{Eu}, \mathrm{Tb}, \mathrm{Yb}$, Lu, and Y) were surveyed from 623 volcanic rock samples (< 33Ma) obtained from the SCS, Hainan Island, Fujian-Zhejiang, Taiwan, Vietnam, and Thailand (Appendix 1).

Appendix 1 The collected analyzed volcanic rocks (<33Ma) from the expansion center of the SCS, seamounts in the SCS, Hainan Island, Fujian-Zhejiang, Taiwan, Vietnam, and Thailand

\subsubsection{Correlation analysis of the original indicators (trace elements)}

Analysis of the correlation matrix of the trace elements of 623 volcanic samples (Appendix 2) reveals that 15 trace elements could be divided into three groups. (1) The first group includes 11 trace elements (Rb, $\mathrm{Nb}, \mathrm{Hf}, \mathrm{Th}, \mathrm{U}, \mathrm{La}, \mathrm{Ce}, \mathrm{Nd}, \mathrm{Sm}, \mathrm{Eu}$, and Tb) with correlation coefficients exceeding 0.6; in fact, most of the correlation coefficients obtained reached 0.9. These findings indicate that the 11 elements are strongly positively correlated and generally enriched or depleted simultaneously. In general, an oceanic island basalt (OIB)-type magmatic source likely causes the enrichment of these 11 trace elements (Sun and McDonough, 1989). Thus, we can preliminarily speculate that this group represents an OIB-type mantle source. (2) The second group includes three trace elements, including $\mathrm{Yb}, \mathrm{Lu}$, and $\mathrm{Y}$, the correlation coefficients of which exceed 0.8. This group may represent enriched mid-ocean ridge basalt (E-MORB)type mantle sources because E-MORB can generally cause the enrichment of $\mathrm{Yb}$, Lu, and $\mathrm{Y}$ contents (Sun and McDonough, 1989). (3) The third group contains only Ba element, which is not significantly correlated with any of the 14 other elements (correlation coefficients $<0.21$ ). This result reveals that Ba element is a good independent indicator. Thus, Ba element may reflect a subduction-related mantle source (e.g., subduction-related fluids or sediments) (Leeman et al., 1994; Brian et al., 2009; Hanyu et al., 2012).

Appendix 2 Correlation coefficients among the original indicators (trace elements)

\subsubsection{PCA calculations and dimensionality reduction}

After data normalization and spatial projection calculations, we obtain 15 PCs with linear expressions for the trace element contents. The proportions of data information explained by each PC are respectively $65.9 \%, 19.3 \%, 6.5 \%, 3.2 \%$, and $1.8 \%$, etc. PCs accounting for over $5 \%$ of the data information are selected for analysis; thus, only the first three PCs, which could explain $91.7 \%$ of the data information, are considered in this work. Table 1 shows the trace element coefficients of these three PCs, which are designated PC1, PC2, and PC3. The Rb, Nb, Hf, Th, U, La, Ce, Nd, Sm, Eu, and Tb coefficients 
corresponding to PC1 have larger positive values compared with those corresponding to PC2 and PC3. The $\mathrm{Yb}, \mathrm{Lu}$, and $\mathrm{Y}$ coefficients corresponding to $\mathrm{PC2}$ have larger positive values compared with those corresponding to PC1 and PC3. The Ba coefficient corresponding to PC3 has a large positive value (Table 1). Thus, the trace elements affecting PC1 are Rb, Nb, Hf, Th, U, La, Ce, Nd, Sm, Eu, and Tb, those mainly affecting $P C 2$ are $Y b, L u$, and $Y$, and that affecting $P C 3$ is $B a$. This analysis is consistent with the findings described in Section 2.1.1. Thus, PC1, PC2, and PC3 may represent an enriched OIB-type mantle source, a depleted MORB-type mantle source, and the involvement of subduction-related fluid/sediment, respectively.

Table 1 Trace element coefficients corresponding to three principal components (PC1, PC2, PC3)

\begin{tabular}{|clll|}
\hline & PC1 & PC2 & PC3 \\
$\mathrm{Rb}$ & 0.242 & -0.187 & 0.150 \\
$\mathrm{Nb}$ & 0.289 & -0.149 & -0.002 \\
$\mathrm{Ba}$ & 0.078 & -0.085 & 0.958 \\
$\mathrm{Hf}$ & 0.275 & -0.094 & -0.106 \\
$\mathrm{Th}$ & 0.282 & -0.181 & 0.031 \\
\hline $\mathrm{U}$ & 0.284 & -0.111 & 0.009 \\
\hline $\mathrm{La}$ & 0.312 & -0.032 & -0.016 \\
\hline $\mathrm{Ce}$ & 0.313 & -0.043 & -0.030 \\
\hline $\mathrm{Nd}$ & 0.314 & 0.000 & -0.059 \\
\hline $\mathrm{Sm}$ & 0.313 & 0.011 & -0.088 \\
\hline $\mathrm{Eu}$ & 0.303 & 0.018 & -0.082 \\
\hline $\mathrm{Tb}$ & 0.293 & 0.163 & -0.078 \\
\hline $\mathrm{Yb}$ & 0.079 & 0.562 & 0.095 \\
\hline $\mathrm{Lu}$ & 0.070 & 0.565 & 0.113 \\
\hline $\mathrm{Y}$ & 0.187 & 0.466 & 0.004 \\
\hline
\end{tabular}

*Each number in the matrix represents the influence degree of PC1, PC2, PC3 on trace elements. For example, the calculation formula of PC1 value is $0.255 \times \mathrm{Rb}+0.301 \times \mathrm{Nb}+0.064 \times \mathrm{Ba}+\ldots+0.140 \times \mathrm{Y}$ (where Rb, $\mathrm{Nb}, \mathrm{Ba}$, and $\mathrm{Y}$ are the standardized chemical contents). 


\subsubsection{Comparison of the combined and standard samples}

We merge similar samples, including those samples with proximate sampling sites and identical lithological features and ages, into 110 combined samples. Five standard samples, including $\mathrm{C} 1$ chondrite, primary mantle, normal MORB (N-MORB), enriched MORB (E-MORB), and OIB, are also selected for comparison. Appendix 3 lists the PC values calculated from the trace elements of the five standard and 110 combined samples. The PC1 value of OIB (1.89) is much higher than its PC2 and PC3 values (0.03 and -0.51$)$. In addition, the PC2 values of N-MORB and E-MORB (2.24 and 0.87 ) are higher than their PC1 and PC3 values (-2.93 and $-0.19 ;-3.01$ and -0.22 ) (Appendix 3 ). This result proves that PC1 and PC2 are closely related to OIB-type and MORB-type mantle sources, respectively, and that PC3 is not strongly correlated with the five standard samples. The results of this analysis are consistent with the results discussed earlier in Sections 2.1.1 and 2.1.2. In addition, the PC2 values of 1, 19-23, and 25 combined samples (1.25-2.41) are higher than their PC1 and PC3 values (<0; Appendix 3), which indicates that these samples are significantly affected by MORB-type mantle sources. 2-11, 33-55, 57-59, 66-72, 7687 , and $89-110$ combined samples are characterized by higher PC1 values compared with their PC2 and PC3 values (Appendix 3), thus suggesting that these samples are mainly influenced by OIB-type mantle sources.

Appendix 3 Principal component values calculated by trace elements of the 5 standard samples and 110 combined samples.

We use cluster analysis to understand the similarity between the combined and standard samples. In the cluster maps obtained (Fig. 2), samples with similar geochemical features are clustered on the same branch. Most volcanic rocks from the SCS and its surrounding regions are clustered on the same branch as the OIB standard sample (Fig. 2), which indicates that deep enriched OIB-type magmatic sources widely affect the volcanic activities of the SCS and its surrounding regions. 1, 19-23, and 25 combined samples are clustered on the same branch as the N-MORB and E-MORB standard samples (Fig. 2), thus revealing that these volcanic samples are mainly affected by MORB-type spreading ridge mantle sources.

Scatter diagrams of the 110 combined and five standard samples (Fig. 3) are constructed on the basis of the PC values (Appendix 3) and clustering analysis results (Fig. 2). These diagrams intuitively show that most volcanic rocks in the SCS and its surrounding regions (black crosses in Fig. 3) are clustered together, which is basically consistent with the PC values of OIB. This finding confirms that volcanic activities around the SCS are closely related to an OIB-type mantle source.

\section{2 $\mathrm{PCA}$ of $\mathrm{Sr}-\mathrm{Nd}-\mathrm{Pb}$ isotopic ratios}


Five isotopic indicators $\left({ }^{87} \mathrm{Sr} /{ }^{86} \mathrm{Sr},{ }^{143} \mathrm{Nd} /{ }^{144} \mathrm{Nd},{ }^{206} \mathrm{~Pb} /{ }^{204} \mathrm{~Pb},{ }^{207} \mathrm{~Pb} /{ }^{204} \mathrm{~Pb},{ }^{208} \mathrm{~Pb} /{ }^{204} \mathrm{~Pb}\right.$ ) were surveyed from 623 volcanic rock samples (<33Ma) obtained from the SCS, Hainan Island, Fujian-Zhejiang, Taiwan, Vietnam, and Thailand (Appendix 1).

\subsubsection{Correlation analyses of the original indicators (isotopic ratios)}

Analysis of the correlation matrix of five isotopic ratios of 623 volcanic samples (Appendix 4) reveals that these ratios could be divided into two groups. (1) The first group includes the isotopic ratios of ${ }^{206} \mathrm{~Pb} /{ }^{204} \mathrm{~Pb},{ }^{207} \mathrm{~Pb} /{ }^{204} \mathrm{~Pb}$, and ${ }^{208} \mathrm{~Pb} /{ }^{204} \mathrm{~Pb}$, the correlation coefficients of which exceed 0.8 . This result indicates that these $\mathrm{Pb}$ isotopic ratios are strongly positively correlated. (2) The second group includes the isotopic ratios of ${ }^{87} \mathrm{Sr} /{ }^{86} \mathrm{Sr}$ and ${ }^{143} \mathrm{Nd} /{ }^{144} \mathrm{Nd}$, the correlation coefficients of which are negative in value (Appendix 4).

Appendix 4 Correlation coefficients among the original indicators ( $\mathrm{Sr}, \mathrm{Nd}, \mathrm{Pb}$ isotopic ratios)

\subsubsection{PCA calculations and dimensionality reduction}

After data normalization and spatial projection calculation, we obtain five PCs with are linear expressions for the isotopic ratios. The proportions of data information explained by each PC are respectively $79.9 \%$, $13.6 \%, 3.7 \%$, and $2.4 \%$, etc. PCs accounting for over $5 \%$ of the data information are selected for further analysis; thus, only the first two PCs, which could explain $93.5 \%$ of the data information, are considered. Table 2 shows the $\mathrm{Sr}-\mathrm{Nd}-\mathrm{Pb}$ isotope coefficients corresponding to these two PCs recorded as PC1 and PC2.

PC2 is characterized with relatively low ${ }^{87} \mathrm{Sr} /{ }^{86} \mathrm{Sr}(-0.665),{ }^{207} \mathrm{~Pb} /{ }^{204} \mathrm{~Pb}(0.195)$, and ${ }^{208} \mathrm{~Pb} /{ }^{204} \mathrm{~Pb}$ isotopic ratios $(0.348)$, a relatively high ${ }^{143} \mathrm{Nd} /{ }^{144} \mathrm{Nd}$ ratio $(0.446)$, and a similar ${ }^{206} \mathrm{~Pb} /{ }^{204} \mathrm{~Pb}$ isotopic ratio $(0.447)$ in comparison with those of PC1 (Table $2 ;{ }^{87} \mathrm{Sr} /{ }^{86} \mathrm{Sr}=0.397,{ }^{143} \mathrm{Nd} /{ }^{144} \mathrm{Nd}=-0.439,{ }^{206} \mathrm{~Pb} /{ }^{204} \mathrm{~Pb}=0.450$, $\left.{ }^{207} \mathrm{~Pb} /{ }^{204} \mathrm{~Pb}=0.470,{ }^{208} \mathrm{~Pb} /{ }^{204} \mathrm{~Pb}=0.476\right)$, thus suggesting that $\mathrm{PC} 2$ represents a relatively depleted MORB-type mantle source (Sun and McDonough, 1989; Zindler and Hart, 1986). PC1 may reflect a slightly enriched OIB-type mantle plume influenced by an enriched mantle 1 (EM1)-type mantle source (Sun and McDonough, 1989; Zindler and Hart, 1986).

Table $2 \mathrm{Sr}-\mathrm{Nd}-\mathrm{Pb}$ isotope coefficients corresponding to two principal components (PC1, PC2) 


\begin{tabular}{|lll|}
\hline & PC1 & PC2 \\
\hline${ }^{87} \mathrm{Sr} /{ }^{86} \mathrm{Sr}$ & 0.397 & -0.665 \\
\hline${ }^{143} \mathrm{Nd} /{ }^{144} \mathrm{Nd}$ & -0.439 & 0.446 \\
\hline${ }^{206} \mathrm{~Pb} /{ }^{204} \mathrm{~Pb}$ & 0.450 & 0.447 \\
\hline${ }^{207} \mathrm{~Pb} /{ }^{204} \mathrm{~Pb}$ & 0.470 & 0.195 \\
\hline${ }^{208} \mathrm{~Pb} /{ }^{204} \mathrm{~Pb}$ & 0.476 & 0.348 \\
\hline
\end{tabular}

\subsubsection{Comparison of combined and standard samples}

We merged similar samples into 61 combined samples. Appendix 5 gives the PC values calculated from the $\mathrm{Sr}, \mathrm{Nd}$, and $\mathrm{Pb}$ isotopic ratios of the 61 combined and five standard samples. OIB and EM1 have relatively high PC1 values (-1.968-5.547; -0.189-2.260; Appendix 5), while MORB has a high PC2 value (-2.536-1.308; Appendix 5). Therefore, we suppose that PC1 likely represents an enriched OIB- and EM1type mantle source and that PC2 represents a depleted MORB-type spreading ridge. This conclusion is consistent with the results described in Section 2.2.2. 1-4, 6-7, 9-12, 16-27, 32-43, 45-46, and 49-61 combined samples have relatively significantly higher PC1 values relative to PC2 values, which indicates that these samples are affected by the OIB- and EM1-type mantle source (Appendix 5; Fig. 4). Scatter diagrams and cluster analysis directly illustrate that these samples are clustered together, consistent with the PC values of OIB and EM1 (black cross in the Fig. 5). These results indicate the samples are related to OIB- and EM1-type mantle sources.

Appendix 5 Principal component values calculated by $\mathrm{Sr}, \mathrm{Nd}, \mathrm{Pb}$ isotopic ratios of the 61 combined samples and 5 standard samples

\section{Discussion}

Trace elements were analyzed using the PCA method, and three PCs that could explain $65.9 \%, 19.3 \%$, and $6.5 \%$ of the variance found were extracted, which are an enriched OIB-type mantle plume source with fairly high trace element contents (PC1), a depleted MORB-type mantle source featuring spreading ridges with enriched $\mathrm{Yb}, \mathrm{Y}$, and Lu contents (PC2), and subduction-related fluids/sediments with large variations in Ba contents (PC3; Table 1). PCA was used to analyze the Sr, Nd, and Pb isotopic ratios, and two PCs were respectively found to explain $79.9 \%$ and $13.6 \%$ of the variance observed, which are a relatively enriched OIB-type mantle plume source containing large amounts of EM1-type components with high 
${ }^{87} \mathrm{Sr} /{ }^{86} \mathrm{Sr},{ }^{207} \mathrm{~Pb} /{ }^{204} \mathrm{~Pb}$, and ${ }^{208} \mathrm{~Pb} /{ }^{204} \mathrm{~Pb}$ isotopic ratios but a low ${ }^{143} \mathrm{Nd} /{ }^{144} \mathrm{Nd}$ isotopic ratio (PC1), a typical depleted MORB-type mantle source with relatively low $\mathrm{Pb}$ and $\mathrm{Sr}$ isotopic ratios and a high $\mathrm{Nd}$ isotopic ratio (PC2; Table 2).

The OIB-type mantle plume revealed by the PC1 values determined from PCA calculations of trace elements and isotopic ratios is the most important magma source dominating volcanic activities in the SCS and its surrounding areas. OIB-type volcanic activities around the SCS are most likely due to the Hainan mantle plume (Hoang and Flower, 1998; Zhou et al., 2009; Zou and Fan, 2010; Wang et al., 2012, 2013; Huang et al., 2013; Liu et al., 2017; Yan et al., 2006, 2018). We can understand the degree of influence of the Hainan mantle plume on volcanic activity in different periods in the SCS and its surrounding areas by comparing the PC1 values of volcanic rocks in different periods (Appendix 6 ). The PC1 values of nine $0-12.6 \mathrm{Ma}$ Hainan Island combined samples are consistently positive and range from 0.38 to 4.62 ; by contrast, the PC1 values of nineteen 4.6-33 Ma Hainan Island samples are negative (-2.66 - -0.44) (Appendix 6; Wang et al., 2012; Liu et al., 2015). This result indicates than an enriched OlBtype mantle plume plays a more significant role in Hainan volcanic activities during the period 0-12.6 Ma than in those during the period 4.6-33 Ma (Appendix 6). The above observations reveal that younger combined samples collected in the same area have higher PC1 values than older samples. Similar phenomena have been observed in the SCS and its surrounding areas, including the seamounts of the SCS, the expansion center of the SCS, Zhejiang-Fujian, Thailand, and Vietnam (Appendixes 6, 7; Supplementary I), thus indicating that the phenomenon is not accidental but, instead, quite common in our study area. We speculate that the influence of the Hainan mantle plume on the Cenozoic volcanic activity in this area gradually strengthened. Specifically, the influence of the Hainan mantle plume on nearby young volcanic activity during the period of $<13 \mathrm{Ma}$ is much stronger than that during the period of $>13 \mathrm{Ma}$ (Appendixes 6, 7; Supplementary I).

PCA is a powerful tool that could reveal the potential mantle sources of Southeast Asian volcanic activities on the basis of geochemical or isotopic indicators. PCA of the trace elements of volcanic samples from Hainan Island, seamounts in the SCS, and expansion center of the SCS yielded two PCs that explained over $85.2 \%$ of the variance observed; these PCs are represented by the red (PC1; enriched OIB-type mantle plume) and blue (PC2; depleted MORB-type spreading ridge) lines in Fig. 6, respectively. The ordinate of Fig. 6 reflects the relative degree of influence of the two PCs on the trace element compositions of the volcanic samples. The figure clearly shows that $<13 \mathrm{Ma}$ volcanic samples from Hainan Island (0-12.6 Ma), seamounts of the SCS (3-8 Ma), and the expansion center of the SCS (7.4$12.8 \mathrm{Ma})$ have similar and high PC1 values $(0.38-4.62,1.38-7.63,5.14)$, which indicates that these sample are similarly affected by the OIB-type mantle plume to the same degree (red lines in the Fig. 6A). The $<13 \mathrm{Ma}$ samples from the expansion center of the SCS (7.4-12.8 Ma) have high PC1 (5.14) and PC2 values (2.25), thus indicating that these samples are simultaneously influenced by the OIB-type mantle plume (red lines in the Fig. 6A) and the MORB-type spreading ridge (blue line in the Fig. 6A). Therefore, the role played by OIB-type mantle plumes in the formation of $<13 \mathrm{Ma}$ volcanic activities in the expansion center of the SCS should not be ignored or underestimated (Fig. 6A). Volcanic activities in the expansion 
center of the SCS are affected by MORB-type spreading ridges and the OIB-type mantle plumes, which confirms the validity of the mantle plume-ridge interaction model in the expansion center of the SCS. In addition, volcanic activities in the expansion center of the SCS during the periods of 7.4-12.8 $\mathrm{Ma}$ and 15-17 Ma showed similar and relatively high PC2 values (2.25; 1.54-2.13; Figs. 6A, 6B), thus revealing that MORB-type spreading ridges played an equally important role in volcanic activities in the expansion center of the SCS during these periods. However, the low PC1 values of 15-17 Ma samples (-2.90 -2.01) but a much higher PC1 value of 7.4-12.8 Ma samples (5.14; Figs. 6A, 6B) indicate that an OIB-type mantle plume began to appear at the expansion center of the SCS after $13 \mathrm{Ma}$, which strongly proves that the extension of the SCS was not triggered by an OIB-type mantle plume. The extension of the SCS appeared to occur prior to the appearance of the mantle plume. Thus, the claim that the Hainan mantle plume led to the expansion of the SCS is not valid.

PCA of the isotopic ratios of volcanic samples from Hainan Island, seamounts in the SCS, and expansion center of the SCS revealed two PCs that explained over $93.5 \%$ of the variance observed; these PCs are represented by the red (PC1; an enriched OIB-type mantle plume containing large amounts of EM1-type components) and blue (PC2; a depleted MORB-type mantle source) lines in Fig. 7, respectively. The ordinate of Fig. 7 reflects the relative degree of influence of two different PCs on the isotopic ratios of the Hainan Island and SCS volcanic samples. Isotopic PCA calculations resulted in the same conclusions obtained from the PCA for trace elements. The <13 Ma volcanic samples obtained from the expansion center of the SCS (7.4-12.8 Ma) are influenced by PC1 (1.342) and PC2 (0.799) (Fig. 7), thus confirming the mantle plume-ridge interaction at the expansion center of the SCS. The PC2 values of the 7.4-12.8 Ma and 15-17 Ma volcanic samples from the expansion center of the SCS are 0.799 and in the range of -0.449 to 1.001 , respectively. These fairly similar PC2 values suggest that MORB-type spreading ridges have almost similar effects on the production of 7.4-12.8 Ma and 15-17 Ma volcanic activity. The PC1 values of 7.4-12.8 Ma samples obtained from the expansion center of the SCS (1.342) are significantly higher than those of the 15-17 Ma samples (-3.875- -1.224), thus suggesting that OIB-type mantle plumes provide more significant contributions to 7.4-12.8 Ma volcanic activities than that to 15-17 Ma volcanic activities. This finding illustrates that the expansion of the SCS is not caused by the Hainan mantle plume.

By the method of the PCA and cluster analysis of trace element and isotopic ratios, the volcanic activities of these regions, which extend from Zhejiang-Fujian in the north to Vietnam-SCS in the south and from Thailand in the west to Southern Taiwan in the east, may be affected by the Hainan mantle plume (Supplementary I). The successful analyses demonstrated in this study reveal that the PCA method is effective and feasible for understanding the geochemical data of volcanic samples and uncovering the geochemical indicators and mantle sources of volcanic activities. Thus, we have obtained a new study method for the analyses of geochemical data. 
Appendix 6 Principal component values calculated by trace elements of volcanic samples from the Hainan Island, Seamounts in the SCS, Expansion center of the SCS, Zhejiang-Fujian, Thailand, and Vietnam

Appendix 7 Principal component values calculated by $\mathrm{Sr}, \mathrm{Nd}, \mathrm{Pb}$ isotopic ratios of volcanic samples from the South China Sea, Thailand, Hainan Island, and Seamounts in the South China Sea

\section{Analytical Method}

PCA is a simple and efficient dimensionality-reduction algorithm that aims to retrieve a small amount of effective information from a dataset of multiple original indicators (e.g., trace elements or isotopic ratios). These effective information are called derived indicators or PCs and indicate the type and nature of a mantle source. Each original indicator is called a dimension; for example, the 15 trace elements analyzed in this work are considered 15 dimensions. The derived indicators can explain all original indicators and ensure that none of the information in the data is lost. In fact, PCA is a spatial projection process. The space formed by the original indicators is non-orthogonal, which indicates a correlation between the original indicators, while the space formed by the derived indicators is orthogonal, which means the derived indicators are independent of each other.

PCA of geochemical data to speculate the magmatic genesis of volcanic activities in the SCS and its surrounding areas may be divided into five steps. (1) Analyze the correlations among the original indicators, determine which of these indicators can be combined into a derived indicator, and preliminarily assess the type of potential mantle source the derived indicators may reflect. (2) Conduct PCA calculations, including normalization of the data, determination of the linear conversion relationship between the derived and original indicators, evaluation of the proportion of each derived indicator necessary to interpret the data information (expressed as a percentage), and calculation of the derived indicator values for each sample. (3) Select only those derived indicators accounting for over $5 \%$ according to the proportion of data information occupied by the derived indicators. Those indicators accounting for less than $5 \%$ are ignored to achieve dimensionality reduction. (4) Determine which magma source is most sensitive to each derived indicator (or PC) according to the conversion relationship between the derived and original indicators, the potential magma sources analyzed in (1), and a comparison with the derived indicator values of the standard samples. (5) Evaluate the spatial influence range and degree of each magma source according to the space distribution of the PC values.

\section{Declarations}

\section{Acknowledgements}

This work was supported by the program for Guangdong Introducing Innovative and Enterpreneurial Teams, Zhujiang Talent Project Foundation of Guangdong Province (Grant no: 2017ZT07Z066), Major 
Projects of the National Natural Science Foundation of China (41590863), Fundamental Research Funds for Young teacher development project (32110-31610351), Double first-class guidance project (3211018841213).

\section{Author contributions}

S.S.C., Z.W.W. and R.G. contributed equally to idea development and the intellectual growth of this paper. S.S.C. and Z.W.W. wrote the main text.

\section{Additional information}

Competing financial interests: The authors declare no competing financial interests.

\section{References}

Abdi, H. \& Williams, L. J. Principal Component Analysis. Wiley Interdisciplinary Reviews: Computational Statistics. 2, 433-459 (2010).

An, A. R., Choi, S. H., Yu, Y. \& Lee, D. C. Petrogenesis of Late Cenozoic basaltic rocks from southern Vietnam. Lithos. 272-273, 192-204 (2017).

Briais, A., Patriat, P. \& Tapponnier, P. Updated interpretation of magnetic anomalies and seafloor spreading stages in the South China Sea: Implications for the Tertiary tectonics of Southeast Asia. Journal of Geophysical Research: Solid Earth. 98(B4), 6299-6328 (1993).

Brian, R. J., Garret, L. H., Clark, M. J., Wes, H., Brian, L. B., Steven, B. S. \& John, W. V. Isotopic and trace element constraints on the petrogenesis of lavas from the Mount Adams volcanic field, Washington. Contributions to Mineralogy and Petrology. 157, 189-207 (2009).

Chen, S. S., Liu, J. Q., Gao, R. \& Wang, Z. W. Geochemistry of Cretaceous basalts from the Ontong Java Plateau: Implications for the off-axis plume-ridge interaction. Chemical Geology. https://doi.org/10.1016/j.chemgeo.2020.119815 (2020).

Fedorov, P. I. \& Koloskov, A. V. Cenozoic volcanism of Southeast Asia. Petrology. 13, 352-380 (2005).

Hall, R. Cenozoic geological and plate tectonic evolution of SE Asia and the SW Pacific: Computer-based reconstructions, model and animations. Journal of Asian Earth Sciences. 20(4), 353-431 (2002).

Hanyu, T., Gill, J., Tatsumi, Y., Kimura, J. I., Sato, K., Chang, Q., Senda, R., Miyazaki, T., Hirahara, Y. \& Takahashi, T. Across- and along-arc geochemical variations of lava chemistry in the Sangihe arc: Various fluid and melt slab fluxes in response to slab temperature. Geochemistry Geophysics Geosystems. 13(10), 1-27, doi:10.1029/2012GC004346 (2012). 
Ho, K. S., Chen, J. C. \& Juang,W. S. Geochronology and geochemistry of late Cenozoic basalts from the Leiqiong area, Southern China. Journal of Asian Earth Sciences. 18, 307-324 (2000).

Ho, K. S., Chen, J. C., Lo, C. H. \& Zhao, H. L. ${ }^{40} \mathrm{Ar}-{ }^{39} \mathrm{Ar}$ dating and geochemical characteristics of late Cenozoic basaltic rocks from the Zhejiang-Fujian region, SE China: eruption ages, magma evolution and petrogenesis. Chemical Geology. 197(1-4), 287-318 (2003).

Hoang, N., Flower, M. F. J. \& Carlson, R. W. Major, trace element, and isotopic compositions of Vietnamese basalts: interaction of hydrous EM1-rich asthenosphere with thinned Eurasian lithosphere. Geochimica et Cosmochimica Acta, 60, 4329-4351 (1996).

Hoang, T., Choi, S. H., Yu, Y., Pham, T. H., Nguyen, K. H. \& Ryu, J. S. Geochemical constraints on the spatial distribution of recycled oceanic crust in the mantle source of late Cenozoic basalts, Vietnam. Lithos. 296-299, 382-395 (2018).

Huang, X. L., Niu, Y., Xu, Y. G., Ma, J. L., Qiu, H. N. \& Zhong, J. W. Geochronology and geochemistry of Cenozoic basalts from eastern Guangdong, SE China: constraints on the lithosphere evolution beneath the northern margin of the South China Sea. Contributions to Mineralogy and Petrology. 165(3), 437-455 (2013).

Huang, X. W., Su, B. X., Zhou, M. F., Gao, J. F. \& Qi, L. Cenozoic basalts in SE China: Chalcophile element geochemistry, sulfide saturation history, and source heterogeneity. Lithos. 282-283, 215-227 (2017).

Leeman, W. P., Carr, M. J. \& Morris, J. D. Boron geochemistry of the central american volcanic arc: constraints on the genesis of subduction-related magmas. Geochimica et Cosmochimica Acta. 58(1), 149-168 (1994).

Li, N., Yan, Q., Chen, Z. \& Shi, X. Geochemistry and petrogenesis of Quaternary volcanism from the islets in the eastern Beibu Gulf: evidence for Hainan plume. Acta Oceanologica Sinica. 32 (12), 40-49 (2013).

Li, C. F., Lin, J. \& Kulhanek, D. K. South China Sea tectonics: Opening of the South China Sea and its implications for Southeast Asian tectonics, climates, and deep mantle processes since the late Mesozoic. Int. Ocean Discovery Program Sci. Prospectus. 349, 1-111 (2014a).

Li, C. F., Xu, X., Lin, J., Sun, Z. \& Zhang, G. L. Ages and magnetic structures of the South China Sea constrained by deep-tow magnetic surveys and IODP Expedition 349. Geochemistry. Geophysics. Geosystems. 15(12), 4958-4983 (2014b).

Liu, J. Q., Ren, Z. Y., Nichols, A., Song, M. S., Qian, S. P., Zhang, Y. \& Zhao, P. P. Petrogenesis of Late Cenozoic basalts from North Hainan Island: Constraints from melt inclusions and their host olivines. Geochimica et Cosmochimica Acta. 152(1), 89-121 (2015). 
Liu, E., Wang, H., Uysal, I. T., Zhao, J. X., Wang, X. C., Feng, Y. \& Pan, S. Paleogene igneous intrusion and its effect on thermal maturity of organic-rich mudstones in the Beibuwan Basin, South China Sea. Marine and Petroleum Geology. 86, 733-750 (2017).

Miranda, J., Crespo, I. \& Morales, M. A. Absolute principal component analysis of atmospheric aerosols in Mexico city. Environmental Science and Pollution Research. 7(1), 14-18 (2000) .

Peng, K., Li, X. \& Wang, Z.W. Hydrochemical characteristics of groundwater movement and evolution in the Xinli deposit of the Sanshandao gold mine using FCM and PCA methods. Environmental Earth Sciences. 73, 7873-7888 (2015).

Shi, H. \& Li, C. F. Mesozoic and early Cenozoic tectonic convergence-to-rifting transition prior to opening of the South China Sea. International Geology Review. 54(15), 1801-1828 (2012).

Shimizu, E., Pior, M. Y. \& Shidouji, T. Color composite of satellite remotely sensed image integrating principal component analysis and normal varimax rotation. Journal of the Japan Society of Photogrammetry. 36(5), 35-41 (2010).

Sun, Z., Zhong, Z., Keep, M., Zhou, D., Cai, D., Li, X., Wu, S. \& Jiang, J. 3D analogue modeling of the South China Sea: A discussion on breakup pattern. Journal of Asian Earth Sciences. 34, 544- 556 (2009).

Sun, S. S. \& McDonough, W. F. Chemical and isotopic systematics of oceanic basalts: implications for mantle composition and processes. Geological Society, London, Special Publications.42 (1), 313-345 (1989).

Tian, Z. X., Yan, Y., Huang, C. Y., Zhang, X. C., Liu, H. Q., Yu, M. M., Yao, D. \& Dilek, Y. Geochemistry and geochronology of the accreted mafic rocks from the Hengchun peninsula, Southern Taiwan: origin and tectonic implications. Journal of Geophysical Research: Solid Earth. 124, 2469-2491 (2019).

Wang, X. C., Li, Z. X., Li, X. H., Li, J., Liu, Y., Long, W. G., Zhou, J. B. \& Wang, F. Temperature, pressure, and composition of the mantle source region of Late Cenozoic basalts in Hainan Island, SE Asia: a consequence of a young thermal mantle plume close to subduction zones?. Journal of Petrology. 53(1), 177-233 (2012).

Wang, X. C., Li, Z. X., Li, X. H., Li, J., Xu, Y. G. \& Li, X. H. Identification of an ancient mantle reservoir and young recycled materials in the source region of a young mantle plume: implications for potential linkages between plume and plate tectonics. Earth and Planetary Science Letters. 377, 248-259 (2013).

Woodruff, C. D. \& Qualls, R. J. Recurrent snowmelt pattern synthesis using principal component analysis of multiyear remotely sensed snow cover. Water Resources Research. 55(8), 6869-6885 (2019).

Yan, P., Deng, H., Liu, H., Zhang, Z. \& Jiang, Y. The temporal and spatial distribution of volcanism in the South China Sea region. Journal of Asian Earth Sciences. 27(5), 647-659 (2006). 
Yan, Q. S., Shi, X. F., Wang, K. S., Bu, W. R. \& Xiao, L. Major element, trace element, and Sr, Nd and Pb isotope studies of Cenozoic basalts from the South China Sea. Science in China Series D: Earth Sciences. 51(4), 550-565 (2008).

Yan, Q., Shi, X., Metcalfe, I., Liu, S., Xu, T., Kornkanitnan, N. \& Zhang, H. Hainan mantle plume produced late Cenozoic basaltic rocks in Thailand, Southeast Asia. Scientific reports. 8(1), 2640 (2018).

Yu, M., Yan, Y., Huang, C. Y., Zhang, X., Tian, Z., Chen, W. H. \& Santosh, M. Opening of the South China Sea and upwelling of the Hainan Plume. Geophysical Research Letters. 45(6), 2600-2609 (2018).

Zhang, G. L., Chen, L. H., Jackson, M. G. \& Hofmann, A. W. Evolution of carbonated melt to alkali basalt in the south china sea. Nature Geoscience. 10(3), 229-235 (2017).

Zhang, G. L., Luo, Q., Zhao, J., Jackson, M. G., Guo, L. S. \& Zhong, L.F. Geochemical nature of sub-ridge mantle and opening dynamics of the South China Sea. Earth and Planetary Science Letters. 489 (1), 145155 (2018).

Zhao, Q. A Review of Principal Component Analysis. Software Engineering. 19(6), 1-3 (in Chinese with English abstract) (2016).

Zhou, H., Xiao, L., Dong, Y., Wang, C. \& Wang, F., Ni, P. Geochemical and geochronological study of the Sanshui basin bimodal volcanic rock suite, China: implications for basin dynamics in southeastern China. Journal of Asian Earth Sciences. 34(2), 178-189 (2009).

Zindler, A. \& Hart, S.R. Chemical geodynamics. Annual Review of Earth and Planetary Sciences. 14, 493571 (1986).

Zou, H. \& Fan, Q. U-Th isotopes in Hainan basalts: Implications for sub-asthenospheric origin of EM2 mantle endmember and the dynamics of melting beneath Hainan Island. Lithos. 116, 145-152 (2010).

\section{Figures}




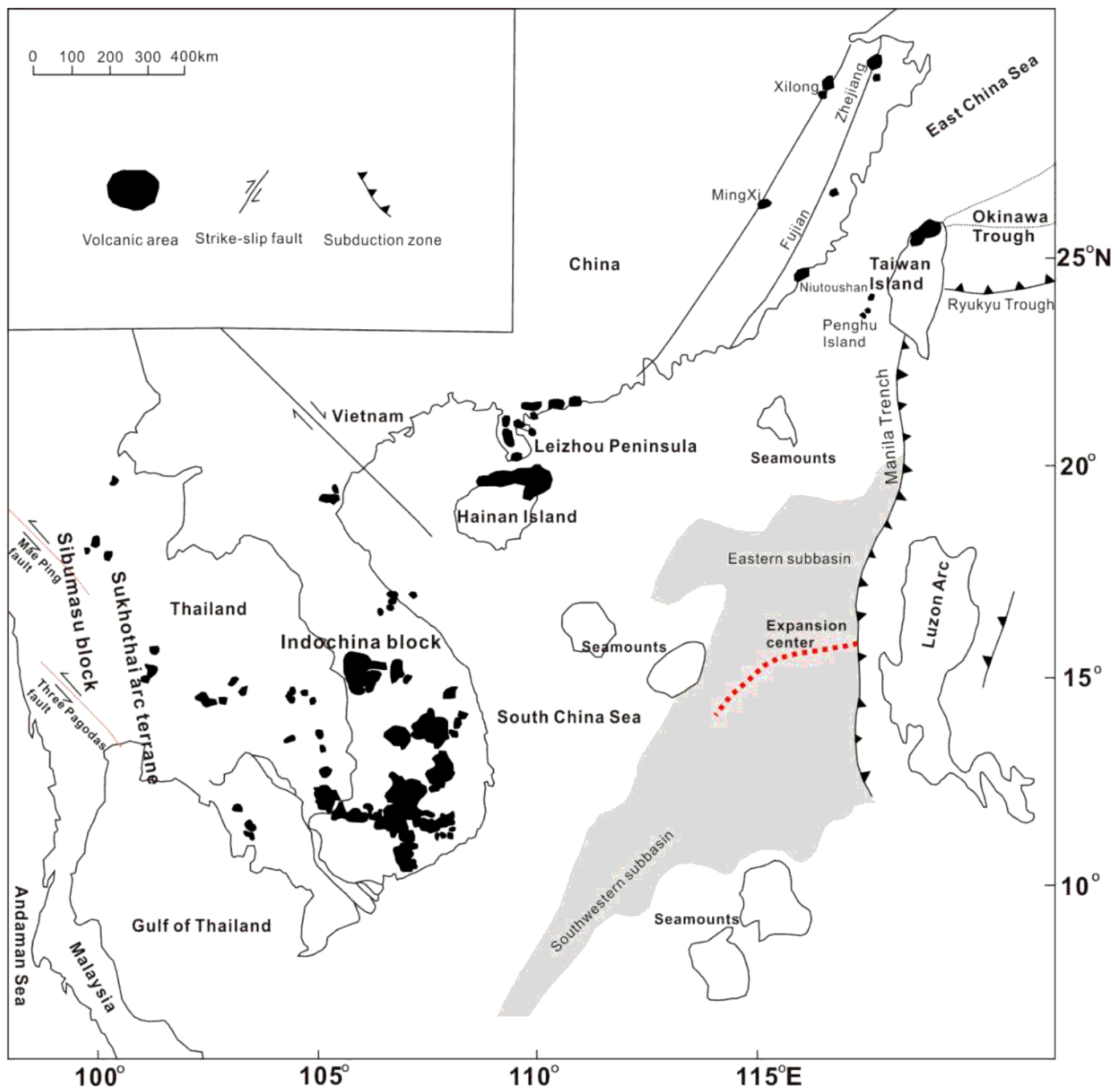

Figure 1

Distribution of Cenozoic volcanic occurrences in Southeast Asia, including the South China Sea, Hainan Island, Fujian-Zhejiang, Taiwan, Vietnam, and Thailand [modified from Fedorov and Koloskov (2005)]. Note: The designations employed and the presentation of the material on this map do not imply the expression of any opinion whatsoever on the part of Research Square concerning the legal status of any country, territory, city or area or of its authorities, or concerning the delimitation of its frontiers or boundaries. This map has been provided by the authors. 


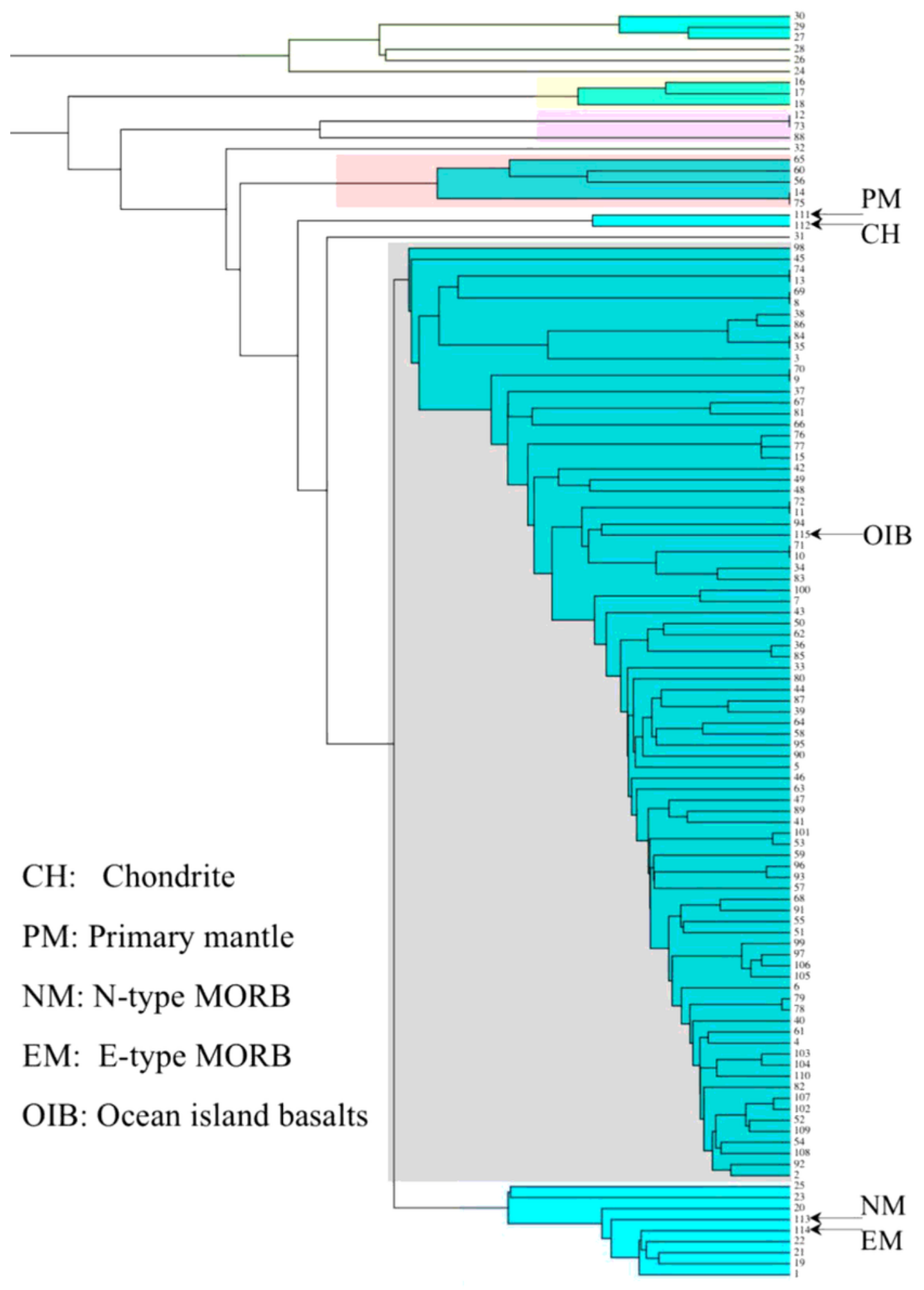

Figure 2

Clustering analysis map of the 110 combined samples and 5 standard samples 

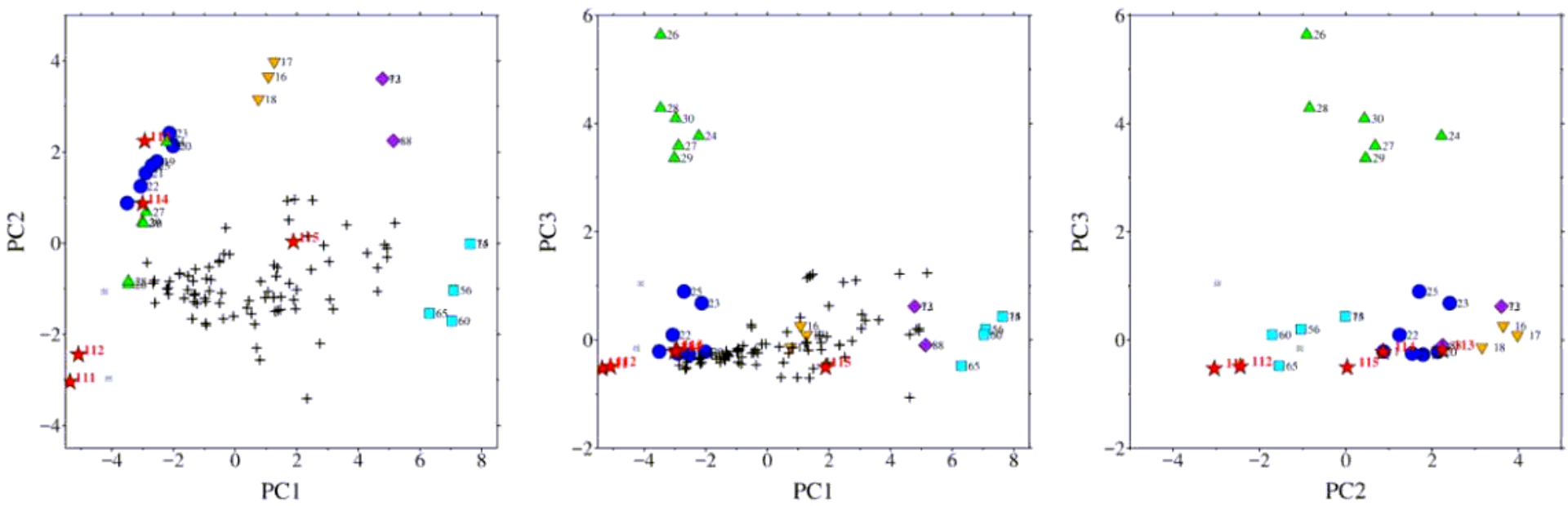

Figure 3

Scatter diagram of the 5 standard samples and the 110 combined samples. Each symbol denotes one cluster obtained by the clustering analysis. The black crosses denote the cluster which is mostly like the OIB sample. 


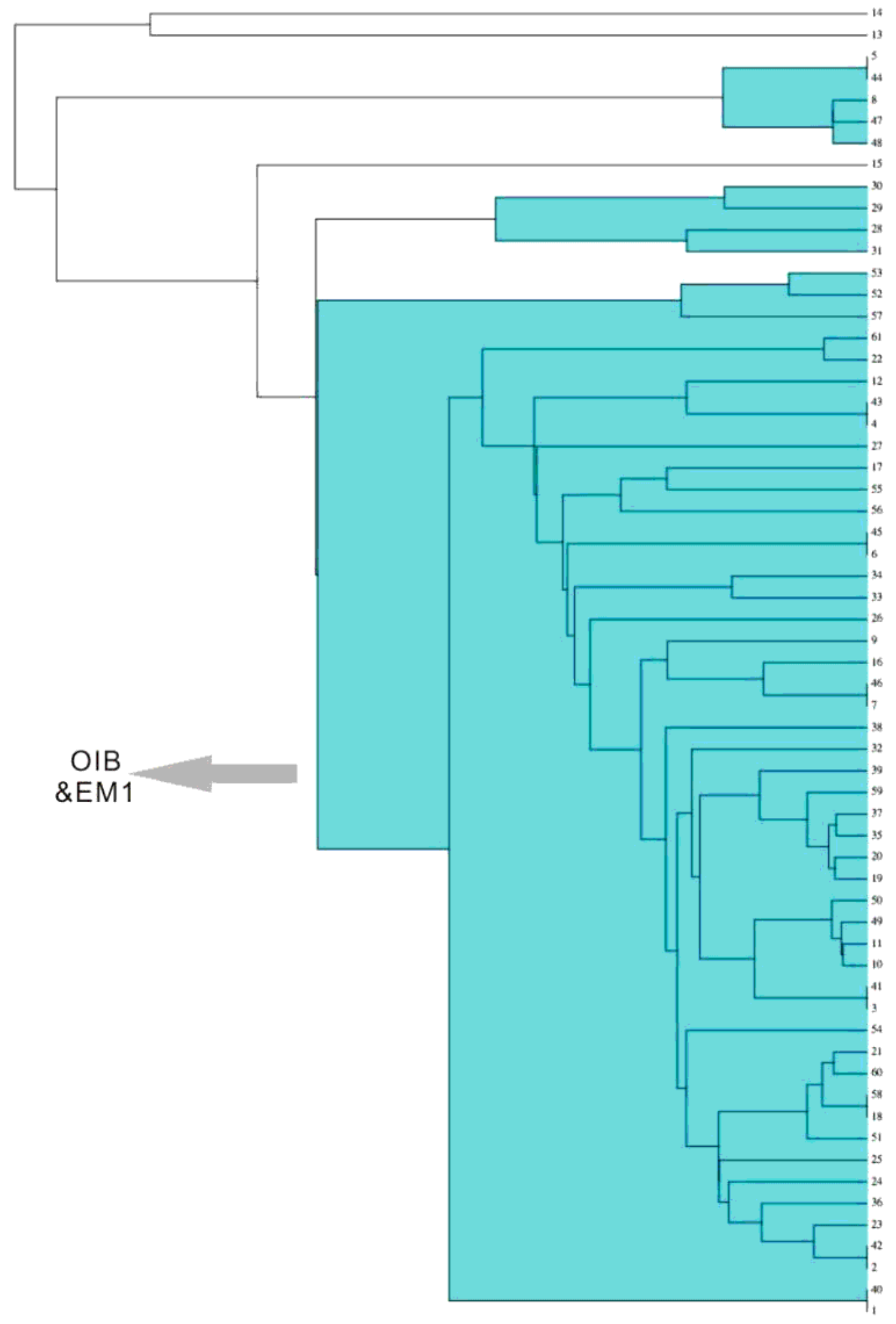

Figure 4

Clustering analysis map of the 61 combined samples 


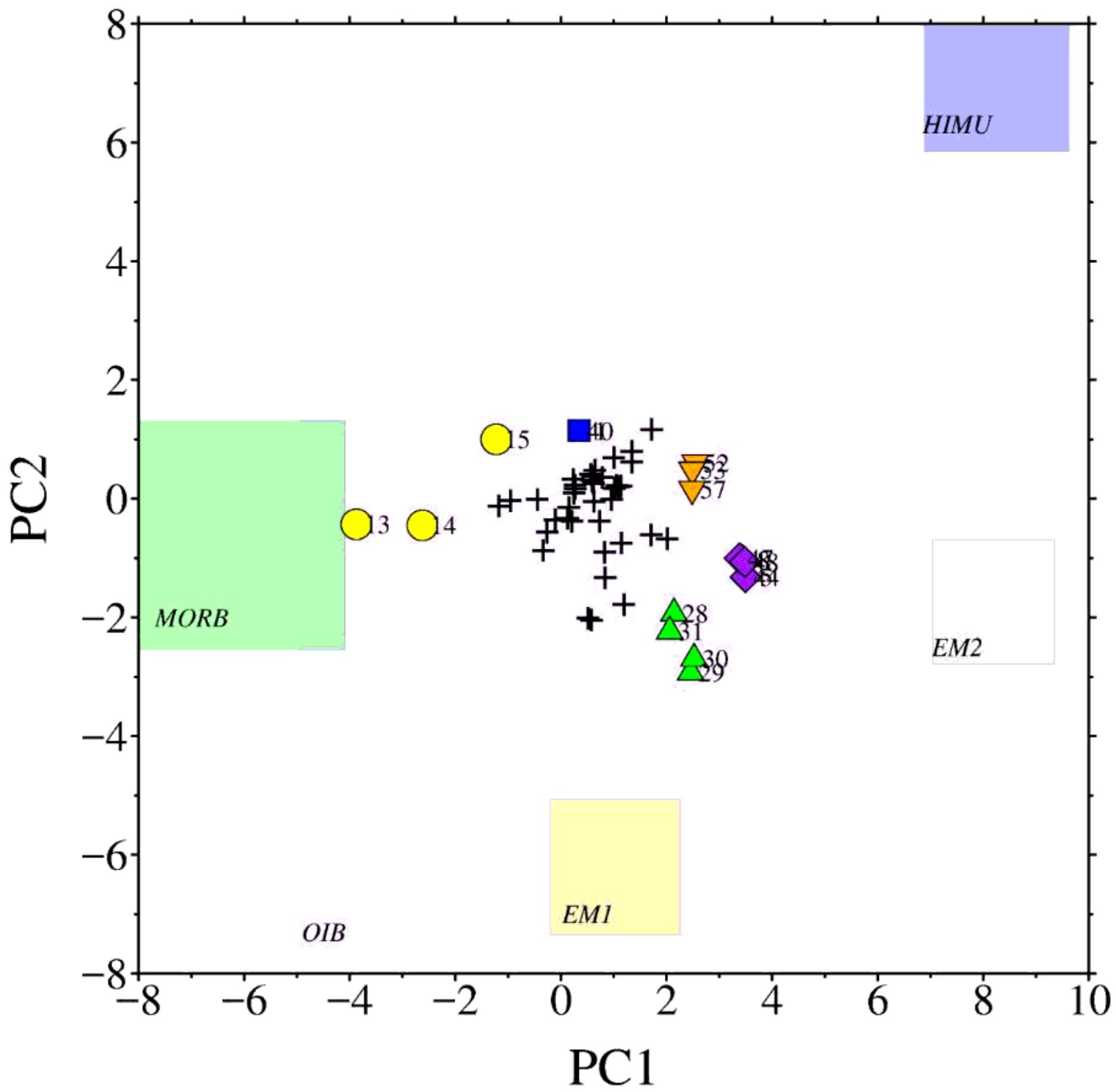

Figure 5

Scatter diagram of the 61 combined samples. Each symbol denotes one cluster obtained by the clustering analysis. The black crosses denote the cluster which is mostly like the OIB-type and EM1-type sample. 

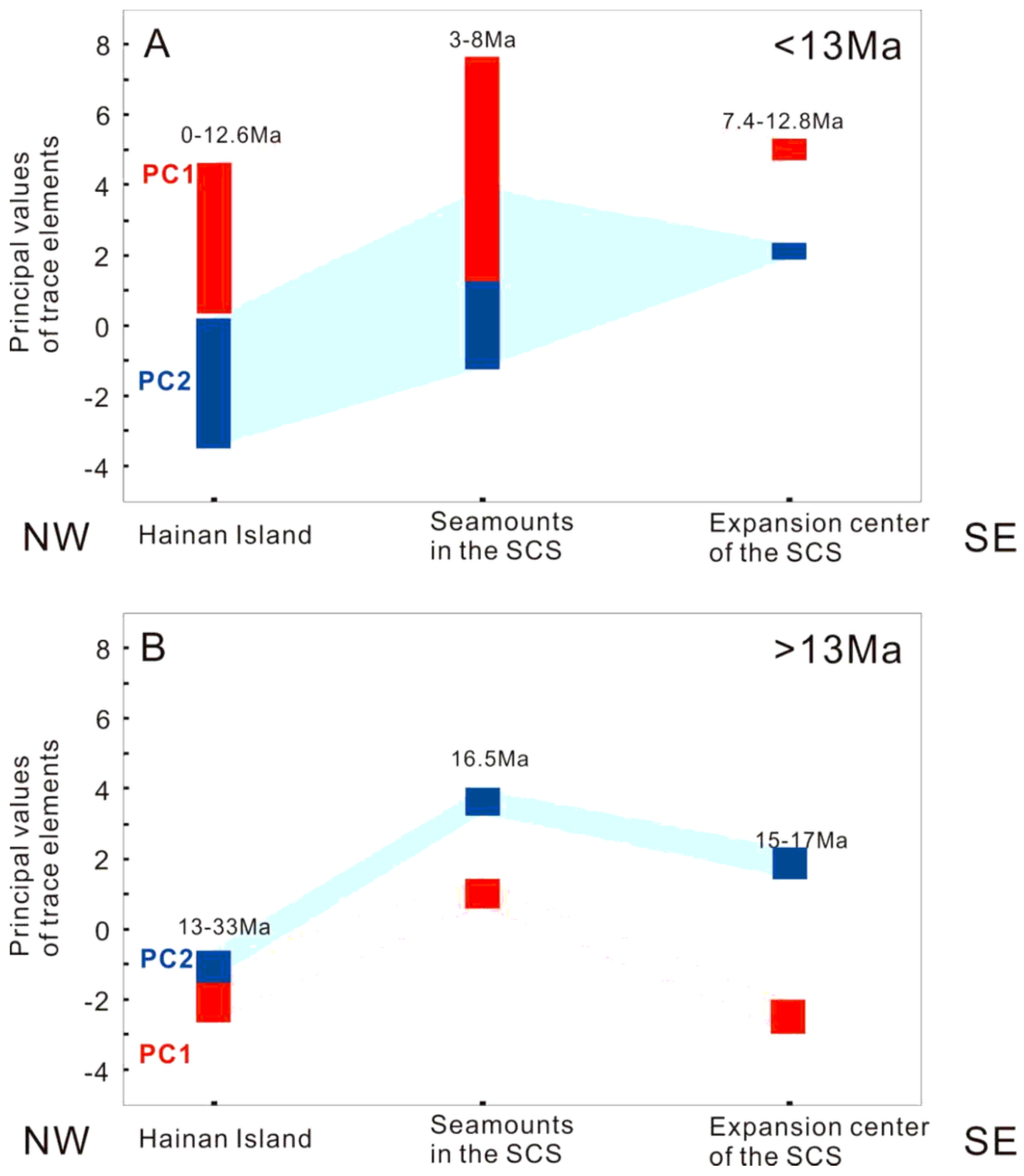

Figure 6

The influence degree of two different PCs (PC1, PC2) on trace element compositions of < 13Ma volcanic samples (A) and > 13Ma volcanic samples (B) from the Hainan Island, Seamounts in the SCS, Expansion center of the SCS, Zhejiang-Fujian, Thailand, and Vietnam 

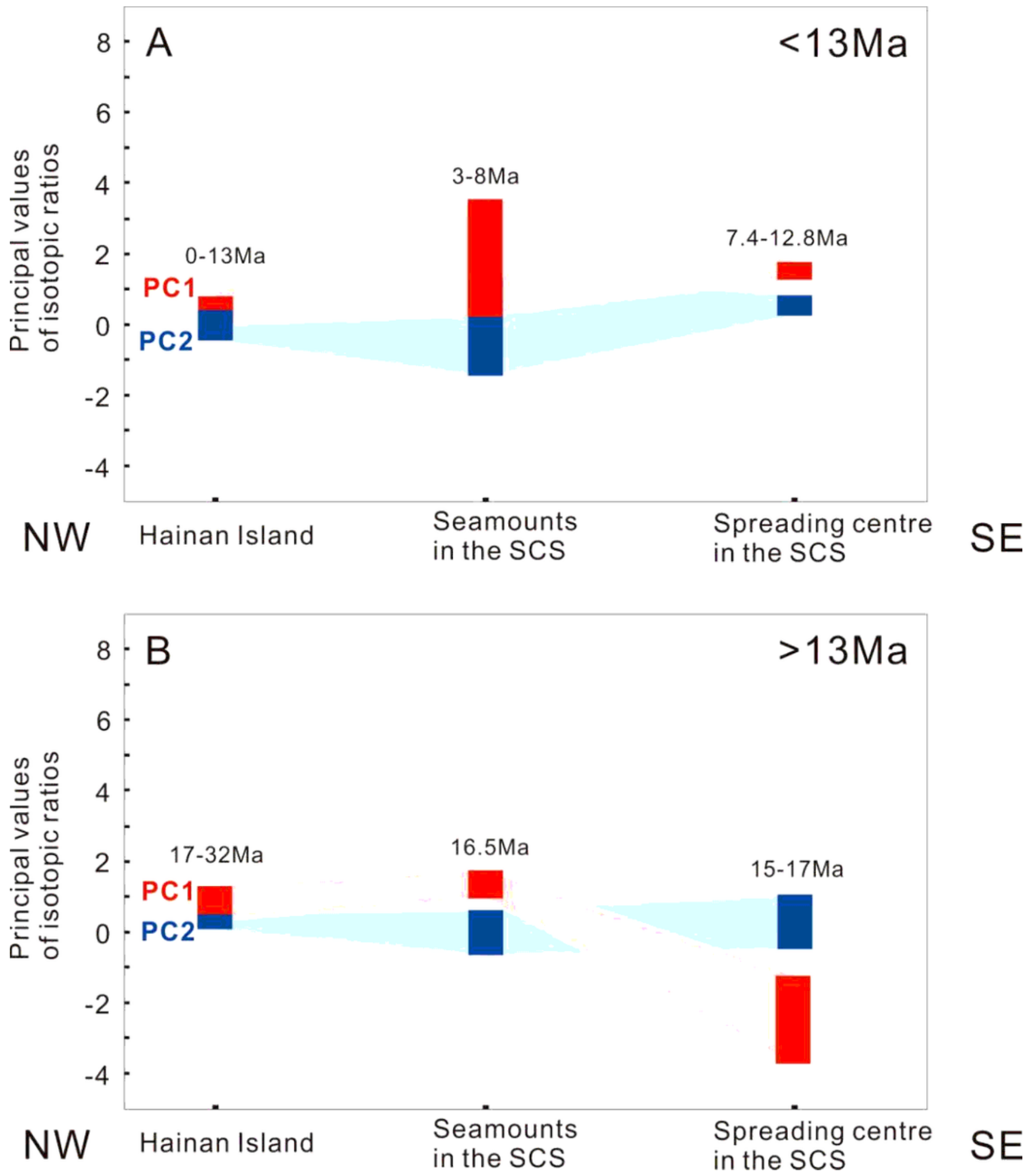

Figure 7

The influence degree of two different PCs (PC1, PC2) on Sr, Nd, Pb isotopic ratios of < 13Ma volcanic samples (A) and > 13Ma volcanic samples (B) from the Expansion center of the SCS, Thailand, Hainan Island, and Seamounts in the SCS 
This is a list of supplementary files associated with this preprint. Click to download.

- FigureS1.docx

- FigureS2.docx

- Appendix1.doc

- Appendix2.doc

- Appendix3.doc

- Appendix4.doc

- Supplementaryl.pdf

- Appendix6.doc

- Appendix7.doc

- Appendix5.doc 